\title{
CAPITAL CORPORAL: UM ESTUDO SOBRE A RELAÇÃO ENTRE CORPO E GÊNERO NA DANÇA DE SALÃO A PARTIR DE UMA PERSPECTIVA SOCIOLÓGICA DE PIERRE BOURDIEU
}

\section{BODY CAPITAL: A STUDY ABOUT THE RELATIONSHIP BETWEEN BODY AND GENRE IN BALLROOM DANCE BASED ON THE SOCIOLOGICAL PERSPECTIVE OF PIERRE BOURDIEU}

\author{
DOI: http://dx.doi.org/10.5965/1984317815022019122 \\ Katiusca Marusa Cunha Dickow \\ Pontifícia Universidade Católica do Rio Grande do Sul \\ katidickow@hotmail.com
}

\begin{abstract}
RESUMO
Este artigo tem o intuito de socializar, como recorte de um projeto de tese, a reflexão sobre a criação e estruturação de disposições inseridas na modalidade de dança de salão desde a sua criação, a manutenção dessas disposições pelos processos formativos e de aprendizagem e de que forma esses elementos codificados são responsáveis por "moldar" os corpos dos sujeitos envolvidos nessa prática, reforçando, dessa forma, conceitos heteronormativos, binários e sexistas. Para essa reflexão, são abordados, a trajetória da dança de salão em seus processos civilizatórios, em articulação com os aportes teóricos de Pierre Bourdieu sobre corpo social e o capital corporal, com o objetivo de identificar como o corpo, como um agente social portador de um habitus, transita no campo em que está inserido e se relaciona com os fatores culturais e temporais. Na pretensão de abrirmos uma discussão sobre o quanto a manutenção desses conceitos pode significar uma violência simbólica e uma relação de poder, impossibilitando que a dança de salão seja uma atividade verdadeiramente aberta a todos.
\end{abstract}

Palavras-chave: Dança de salão. Corpo social. Habitus. Capital corporal.

\begin{abstract}
This article intends to socialize, as a thesis clipping a Thesis project, the reflection on the creation and structuring arrangements included in the ballroom dance modality since its creation, the maintenance of these arrangements by the formative and learning processes and of which these coded elements are responsible for "shaping" the bodies of the subjects involved in this practice, thus reinforcing heteronormative, binary and sexist concepts. For this reflection, the trajectory of ballroom dance in its civilizing processes, in articulation with the theoretical contributions of Pierre Bourdieu on social body and corporal capital, is addressed, with the objective of identifying how the body, as a social agent with a habitat, transits the field in which it is inserted and relates to the cultural and temporal factors. In the pretension of opening a discussion about how the maintenance of these concepts can mean symbolic violence and a power relationship, making it impossible for ballroom dance to be an activity that is truly open to all.
\end{abstract}

Keywords: Ballroom dance. Social body. Habitus. Body capital. 


\section{INTRODUÇÃO}

Existem indícios de que o homem dança desde os tempos mais remotos. Todos os povos, em todas as épocas e lugares dançaram, para expressar revolta ou amor, reverenciar ou afastar deuses, mostrar força ou arrependimento, rezar, conquistar, distrair, enfim, viver (TAVARES, 2005). As peculiaridades dessa manifestação, que permeia a humanidade desde os primórdios e que teve sua expressão em todas as civilizações, cada qual com seu aspecto e sua finalidade, torna inegável a sua influência na vida das pessoas ao longo dos tempos, em cada sociedade.

E, justamente, por se tratar de um reflexo da sociedade e por nela estar inserida, é que, todos nós, em algum momento específico de nossas vidas, já tivemos contato com alguma manifestação de dança, seja por meio de uma apresentação, um filme, espetáculo, festa, ou qualquer outra forma. Ela está presente em nossas vidas e, seja como espectador ou participante, podemos elencar inúmeros benefícios físicos e emocionais, como: saúde, bem-estar, socialização, lazer, prática de atividade física e contemplação, sendo considerada uma atividade artística e cultural, pela relação entre o indivíduo e a reflexão de si mesmo e sua interação social (VECCHI, 2012).

Quando falamos em dança de salão ou danças a dois, diversas imagens ou definições vêm em nosso pensamento e essas atribuições estão diretamente relacionadas à experiência que tivemos com essas manifestações socais, porém, é inegável que o ato de dançar a dois envolve não somente uma atividade social, mas sim todo um ritual que tem início desde a escolha da roupa, do sapato, o convite para bailar e a intensidade de sentimentos que se misturam a cada dança, porque cada uma delas possibilita sensações das mais diversas para os sujeitos envolvidos, expressando toda a complexidade esse campo social.

Uma escolha importante para a identificação e análise desse campo foi a distinção, na perspectiva dessa pesquisa, das danças a dois em duas vertentes: a dança social e a dança de salão. Como resultado de diversas pesquisas foi possível perceber que as definições das danças de salão são divergentes entre os autores e 
não existe um consenso entre os conceitos de dança de salão, dança social, popular ou folclórica, como podemos perceber nas citações desses autores: Segundo Faro \& Sampaio (1989) o termo dança folclórica surgiu para diferenciar as danças do povo das danças das classes altas e é uma das manifestações populares de um país, que não sofre a intervenção de um coreógrafo, sendo transmitida entre as gerações por meio da tradição. De acordo com Ried (2003) as danças de salão se originaram de causas sociais, políticas e eram praticadas com objetivos de socialização e diversão propiciando o estreitamento das relações sociais de romance e amizade. Já Faro (1989) afirma que a dança de salão é a designação de todos os tipos de dança sociais, executadas por pares em bailes ou reuniões. Segundo Ried (2003) as classes nobres se diferenciavam das classes baixas através das danças típicas. Os aristocratas eram praticantes das danças de corte, enquanto o povo dançava as danças folclóricas. E Ellmerich (1964) defende a ideia da dança social como um agrupamento de pares que tinha como objetivo a inteiração social e caracteriza-se por uma atuação dos homens diferente da atuação das mulheres.

Nesse sentido, faremos uma distinção entre a dança social e a de salão baseado nos fatores que auxiliarão as reflexões da pesquisa, levando em conta a diferenciação de disposições que regulam esses campos sociais, sem desconsiderar os inúmeros aspectos que envolvem as definições desses termos. Por exemplo, as danças sociais surgem da miscigenação de culturas, geralmente das classes populares e, por conta disso, apresentam estruturas mais livres e cambiáveis que se moldam a aspectos culturais, temporais e físicos. Essas estruturas são aprendidas e vivenciadas culturalmente por um processo de aprendizagem mimético, que envolve formas de saber prático, ao longo de processos que envolvem o corpo e os sentidos, permitindo agira com tranquilidade dentro das organizações e das instituições (WULF, 2016).

Já a dança de salão e seus gêneros específicos, apesar de na maioria das vezes surgirem das mesmas manifestações populares que as danças sociais, estão vinculadas ao aprendizado de estruturas mais rígidas em seu processo de ensino por caracterizarem a aquisição de uma técnica específica que envolve o saber fazer de 
habilidades, discursos e gestos em todos os ambientes considerados como parte desse campo: aulas de dança, bailes, shows, competições, eventos e mídias sociais.

Dessa forma, não podemos dizer que um baile de dança de salão é igual a uma festa social, porque neles estão inseridas disposições que se diferem pela maneira com que são dispostas e absorvidas pelos agentes inseridos nestes dois contextos sociais, fazendo-se perceber que, mesmo que uma dança social seja executada em um salão, ou uma dança de salão possa ser dançava em um evento social como uma festa, aniversário ou casamento, elas se distinguirão por suas estruturas, gestos e figuras resultantes das disposições contidas em cada campo.

Para Marion (2008), a prática de dança de salão constitui uma enorme comunidade, definida em uma trama complexa de profissionais e instituições, com hábitos definidos, que formam suas subjetividades. Essas comunidades somam uma força de pensamentos e ideias, fabricando "identidades" que se reproduz nos seus elementos constituintes, dentro de um campo que, segundo Bourdieu (2011, p.47), "representa um espaço simbólico, no qual as ações dos agentes determinam, validam, legitimam, representações, estabelecendo assim, uma classificação dos signos, pertencentes ou não a um código de valores". Nesse sentido podemos identificar que a dança de salão e suas especificações de gêneros musicais (samba, tango, salsa, bolero, forró, entre outros), praticada em diversos países ocidentais e orientais, constitui um campo social edificado por disposições e códigos que transpassaram as barreiras territoriais e culturais, tornando esse campo uníssono, independente dos locais onde suas práticas sejam reproduzidas.

\section{A DANÇA DE SALÃO E OS SEUS CÓDIGOS}

Como exemplo dessas disposições, que permeiam e estruturam a dança de salão, podemos relacionar características como: o sentido em que se gira no salão, que é anti-horário e utilizado como regra em todos os salões de dança de salão; o ato de o homem convidar a mulher para bailar, conduzindo-a até a pista e retornando com ela, 
no final da dança, para o mesmo lugar onde a convidou; o abraço que é padronizado e tem a mesma forma e função em todas as danças com definições de 'abraço fechado' (bolero, tango, samba, valsa, forró, entre outras); a representatividade de gênero e o binarismo relacionado à figura do homem a da mulher, que tem grande força de determinismo na criação dos passos e sequências utilizados pelos praticantes. Diante desses aspectos surge o questionamento de onde surgiram essas disposições e de que forma elas foram edificadas?

Historicamente, o ato de se dançar a dois, nos períodos anteriores ao século XI, padece de registros em livros e artigos sobre o tema, fazendo com que a investigação sobre as formas, as ocasiões e as características desse ato, se torne praticamente nula. Dos escassos registros encontrados nas bibliografias relacionadas à história da dança (ELLMERICH, 1964; CAMINADA,1999; BOURCIER 2011), podemos chegar a conclusão que, as danças a dois, tomam forma, como modos de lazer e representação cultural, a partir do século $\mathrm{XI}$, em rondas campesinas, onde homens e mulheres já se reconheciam como pares, porém, não havia nesse tipo de manifestação, duas características marcantes, que surgirão posteriormente nas danças de corte: 0 galanteio e a sedução, como sugere Caminada (1999).

Essa atividade, que começa a ser praticada na Europa, no século XI, pelos camponeses, em festividades que celebravam as colheitas, casamentos, aniversários e outros eventos sociais é, posteriormente, no século XII, pelas transformações ocorridas na sociedade europeia, principalmente na França, reorganizada em uma visão de dança diferente, onde as haute danses (dança altas), com estruturas mais livres e improvisadas foram modificadas para estruturas mais codificadas e repletas de códigos, chamadas de basse danses (danças baixas). Essas transformações dividiram a dança em duas correntes: a dança popular, expressa pelos camponeses na manutenção de seus costumes, com movimentações mais livres e estruturas mais maleáveis, e a dança cortesã, realizada de forma metrificada e estilizada pelos nobres cortesãos da classe alta (DICKOW, 2010). 
As danças de corte, e as modificações realizadas, para que essa dança fosse praticada pela aristocracia, são um reflexo da sociedade europeia, o chamado Renascimento marca uma transformação no modo de viver do cidadão europeu, o aspecto físico e estrutural das cidades se modifica, a arte importada da Itália vem culminar no pensamento francês de ostentação da beleza, do prazer e da aquisição de poder, enquanto a dança cortesã expressa a soberania e expressividade desse poder, por meio da conduta de domínio e absolutismo do homem diante da fragilidade e passividade da mulher (NUNES, 2016).

Após longos anos de prática nos salões da corte europeia, a dança de salão atravessa o Atlântico por dois caminhos, através dos bailes de salão reproduzidos pela burguesia e pelo viés do espetáculo que dará origem ao que hoje conhecemos como dança clássica, iniciando pela França e mais diretamente, justamente pela colonização, Espanha e Portugal. Ao chegar aos seus destinos, elas se instalam, passam pelos processos de incorporação e transformação, se mesclando as danças já existentes nas sociedades onde foram inseridas, porém, a maioria delas conservou, até hoje, muitos dos códigos e estruturas que caracterizam a época e sociedade em que surgiram. Como exemplo podemos citar a valsa que é considerada a primeira dança de pares enlaçados que até hoje é reproduzida em eventos sociais como casamentos e festas de 15 anos com as mesmas características de sua criação: formato do abraço, distância entre o par, elegância e requinte.

Vale aqui ressaltar que essas estruturas fixas e disposições são constituintes dos processos de aprendizagem, que iniciaram sua trajetória com os mestres de dança através dos tratados de dança, como o Orchésographie, que em 1589 já registrava instruções relacionadas à dança e a etiqueta das cortes europeias (NUNES, 2016) e seguiram seu fluxo nas formatações de outras instituições como as escolas de dança, as academias, aulas online.

Disposições essas que se destacam principalmente no que se refere a relação homem/mulher, cavalheiro/dama, traduzidos na forma de construção da ação de conduzir e responder dessa participação ativa versus passiva e heteronormativa da 
dança de salão que também estão associados as relações de poder absorvidas culturalmente nessa relação. Cavalheiro e dama são duas expressões muito comuns no universo da dança de salão e até hoje utilizadas nos modelos de aprendizagem dessa modalidade, designando assim a dama como o papel feminino, na posição de quem espera a condução do cavalheiro e o próprio, na posição de quem comanda a dança, de referência masculina.

Constituindo assim, "uma cultura dançante que perpassa os anos e mantém estagnadas estruturas e códigos correspondentes a época em que foi criada, estando sempre associada à demarcação de classe social e papéis de gênero" (MARION, 2008, p. 11), reafirmando-se como um dispositivo pedagógico e estético dessa demarcação, em contraponto com os scripts de gênero que já não se encaixam nos padrões de binaridade.

Disposições que, ao serem vivenciadas e reproduzidas pelos sujeitos envolvidos nessa modalidade de dança, acabam por criar estereótipos responsáveis por frases como "dama boa não pensa" (PERNA, 2012, p. 49.), "a dama é que gira", "a dama precisa obedecer o cavalheiro" e, ao refletir sobre essas expressões, podemos verificar que o problema não está somente nas expressões em si mas sim no sentido e significado que foram atrelados a elas, assim como todos os possíveis códigos heteronormativos que reforçam a rotulação de gêneros e relações de poder inseridas nos corpos dos sujeitos envolvidos nessa prática dançante, reforçando a dança de salão como uma prática cultural que há muitos anos evidencia estereótipos de gênero e insere no corpo o comportamento e a gestualidade que procedem de códigos binários, patriarcais e heterossexistas. "Ensinar uma mulher a ser dama e um homem a ser cavalheiro, é análogo a ensinar a uma menina que ela deve gostar de bonecas e cores suaves, e a um menino que ele não pode chorar" (PAZETTO; SAMWAYS, 2018, p. 162).

A dança de salão quando não associada ao processo coreográfico, que possui a característica de estruturas determinadas e decoradas em sequência, e sim ao improviso que trabalha com a escolha momentânea dessas estruturas, tem por 
característica o processo contínuo entre estímulo e resposta dessas estruturas. $\mathrm{Na}$ grande maioria dos processos essa função do estímulo está associada à figura do homem ou cavalheiro como condutor do processo e à mulher ou dama se dá a função de receptora dessa informação. Se pensarmos nesse processo de estímulo e resposta como um diálogo, nada foge da normalidade entre o comunicador e o receptor da mensagem, aqui obviamente ligada à questões não verbais, porém, quando ele está vinculado a características e estereótipos da binarismo de gênero associado ao comando (homem) e a recepção (mulher), nos deparamos com valores bem mais intrínsecos que estão relacionados a determinismos culturais que definem esses sujeitos e que refletem diretamente nesse diálogo, evidenciando a figura feminina como algo frágil, passivo e sedutor.

Independente de que um dos objetivos de se dançar a dois possa ser o galanteio e a sedução, compreende-se que esse ato constitui um processo de características e intenções bem mais amplas do que esses e não necessariamente precisa estar associado à conquista ou a libido, nem a condições heteronormativas, abrindo dessa forma caminhos para que a dança de salão possa ser vista como uma atividade disponível a todos e que para isso a pessoa não precise se adaptar a disposições e códigos que a distanciam dessa prática e rotulam seu corpo a um binarismo tão enraizado em nossa cultura.

Conseguimos visualizar que distintos caminhos já estão sendo explorados e estimulados por diversos profissionais da dança de salão no Brasil, como é o caso das pesquisas realizadas pelos autores (FEITOZA, 2011; SILVEIRA, 2012; STRACK, 2013; NUNES, 2016; POLEZI, 2017; PAZETTO \& SAMWAYS, 2019), referentes à dança queer, a condução compartilhada e outros assuntos onde são discutidos e vivenciados diferentes possiblidades de se dançar a dois e de se refletir sobre esse campo social. Porém, essas iniciativas ainda se defrontam com ideias estacionárias que se opõem a essas reflexões alicerçadas por afirmativas de que as estruturas da dança de salão já existem há muito tempo e não precisam ser modificadas ou que esses modos de 
pensar podem distanciar as características fundamentais da dança de salão de suas raízes.

Nesse sentido, esses códigos e disposições relacionadas aos gêneros e sua identidade na sociedade, ainda muito presentes nos pensamentos, discursos e por consequência nos gestos do universo da dança de salão refletem em estereótipos de expressões ainda muito comuns nos processos de aprendizagem da dança de salão e, por consequência, todos os âmbitos que envolvem essa prática, como: "na dança o homem é quem manda", "mulher tem que ser bem mandada", "domina ela direito" e assim por diante.

Se esses códigos são traduzidos em discursos e esses discursos são traduzidos em práticas, nos resta questionar e refletir, de que forma esses conceitos 'marcam' os corpos desses sujeitos envolvidos nessa prática?

\section{CORPO SOCIAL E CAPITAL CORPORAL}

Na tentativa de auxiliar essa reflexão, procurou-se a compreensão de alguns conceitos recorridos do aporte teórico do sociólogo Pierre Bourdieu e seu importante estudo sobre habitus, campo, corpo social e capital corporal. Conceitos esses que nos trazem a possibilidade de uma reflexão sobre as estruturas da dança de salão, a partir de um olhar sobre os sujeitos envolvidos nesse campo.

De uma perspectiva social, o corpo pode ser interpretado por suas relações e expressões no coletivo em que está inserido. As experiências são incorporadas de modo objetivo e subjetivo pelos sujeitos que, de certa forma, vão acumulando gestos e maneiras de ser corporalmente. Podendo o corpo ser visto como instrumento e produto de uma construção social por seu habitus, que carrega as marcas da significação social que lhe é atribuída. Segundo Bourdieu (1983, p.65) o habitus pode ser entendido como "um sistema de disposições duráveis e transponíveis que, integrando todas as experiências passadas, funciona com uma matriz de percepções, que torna possível a realização de tarefas infinitamente diferenciadas". 
Nesse sentido, o corpo passa a ser a primeira experiência na relação com o mundo. Um corpo tocante tocado que prioriza não o que se vive, mas sim, um pensamento cognitivo que se estrutura por esse viver corporal numa ideia de 'verdade' que é adquirida e subjetivada no sentir. As propriedades dos objetos do conhecimento são incorporadas e (re)codificadas pela experiência corporal. Na aprendizagem se coloca em jogo um sujeito e um sentir e é, justamente, a relação do corpo com o mundo, que possibilita a comunicabilidade dessa expressão, pelo pertencimento a esse corpo situado, na medida em que se vivencia o mundo de forma afetiva e perceptiva, invadindo a experiência de si mesmo e dos outros.

$\mathrm{Na}$ medida em que o corpo percebe o mundo conforme uma atitude perceptiva, tal atitude envolve a expressão, dessa maneira, o corpo se expressa conforme o movimento perceptivo que realiza no mundo, por meio de uma atitude motora, um gesto, inter-relacionando a prática com o sentido. O corpo expressa sua percepção na medida em que se comunica com os outros, situando-se no mundo sensível, que lhe faz sentido. Essa expressão, antes mesmo das palavras, é a percepção do mundo, podendo afirmar que, o gesto com o qual o corpo se comunica no mundo, é a atitude perceptiva manifesta intersubjetivamente, ou ainda, a expressão do ser no mundo.

Nos estudos de Bourdieu, podemos perceber como são frequentes as abordagens relacionadas as questões corporais, principalmente quando relacionadas a corporeidade intrínseca, resultante do contato subjetivo entre sujeito e objeto, identificando o corpo como uma fonte de uma intencionalidade prática. Podemos observar nessas abordagens que as relações corporais entre o sujeito e o objeto podem acontecer de uma forma intrínseca quando pensada sobre o olhar do agente social com um indivíduo resultante do seu habitus e a sociedade em que está inserido, interferindo diretamente na forma de ver e se relacionar com o outro.

Milstein e Mendes (2010) desenvolvem a ideia de corporização, como uma intrínseca relação entre as elaborações práticas e os vínculos, criados a partir do contato do corpo-sujeito, com o tempo, o espaço, os objetos e suas intencionalidades, 
sendo possível por esse prisma visualizar o corpo como o resultado de um processo da natureza e de uma construção histórica e cultural.

Nessa perspectiva, podemos entender que o corpo, portador do habitus, tornase social à medida que vai moldando em si mesmo as condições materiais e culturais, em um contexto socializador que produz um ser individual forjado nas e pelas relações sociais, podendo ser exemplificado ao direcionarmos nosso olhar para o contexto histórico e cultural da época e local de criação das danças de salão, onde as transformações dos espaços urbanos e modos de vida, da civilização camponesa para a urbana, exigiram a elaboração e incorporação de novas atitudes corporais, demandando nesse sentido, mudanças de natureza (BOURDIEU, 2006).

Imbricado nesse contexto, o agente aprende e define o seu modo de agir, de se relacionar e principalmente de se expressar, definindo o corpo social como o corpo do indivíduo portador do habitus que se molda a um sistema de disposições duradouras que são incorporadas por meio práticas reguladas e estruturadas.

Essas imbricações dos conceitos de Bourdieu sobre as relações do corpo social, trabalham como balizadoras nas reflexões sobre o processo de se dançar a dois, a criação das chamadas danças de salão e os sujeitos envolvidos nessa prática em sua relação com o ser social, com o sujeito e seu corpo e de que forma essas conexões nos auxiliam a entender o contexto que se constrói nos encadeamentos dessas possibilidades.

Refletindo sobre a somatização de relações de dominação que podem acontecer pelo corpo, podemos interconectar três aspectos fundamentais do pensamento relacional de Bourdieu, disposição/habitus, situação/campo e bens simbólicos/capital. Esses três aspectos, quando olhados pelo prisma da corporeidade podem ser entendidos na forma de um capital corporal justamente por representar e, ao mesmo tempo, validar o entendimento desses vetores.

Para Bourdieu (2002, p. 65), "a partir do adestramento dos corpos é que se impõem as disposições mais fundamentais, ao mesmo tempo que torna o indivíduo 
apto a entrar nos jogos sociais". Esses jogos sociais funcionam como uma negociação, a partir da obtenção de trunfos em forma de bens ou capitais, como o capital corporal.

Podemos pensar as dimensões corporais, na sociologia bourdieusiana, relacionadas ao três aspectos citados anteriormente, habitus, campo e capital, desenhadas da seguinte forma: primeiramente, o corpo adquire e incorpora valores (habitus primários e secundários) fazendo com que sua resposta a situações do meio social deixe de ser um reflexo para virar uma automatização relacionada a uma construção social desse corpo.

Esse corpo é moldado por meio do campo ao qual pertence, como por exemplo, a classe social, através de escolhas utilizadas na contribuição da "moldura" desse corpo. Escolhas essas que se referem a habilidades motoras, atividades físicas, práticas alimentares, revelando o "esquema corporal" como depositário de toda uma visão do mundo social e de pertencimento a um grupo social (MEDEIROS, 2011).

E por último, as maneiras de ser, de pensar, de perceber e de agir, entendidas como habitus, são percebidas como um conjunto de reações que são insufladas nos sujeitos por meio da socialização, que é responsável pela construção desse capital corporal e por modelar seu modo de pensar, de agir e reagir. Esse pertencimento social leva o corpo a se tornar o local de reprodução das formas de dominações sociais, físicas e simbólicas, um mecanismo privilegiado para o exercício da violência simbólica de posições hierarquizadas. Para Bourdieu "a violência simbólica é uma violência que se exerce com a cumplicidade tácita daqueles que a sofrem e também daqueles que a exercem na medida onde uns e outros não têm consciência de exercê-la ou de sofrê-la" (BOURDIEU, 1995, p.55).

Ao falarmos de capital corporal, acredita-se ser necessária a identificação dos sujeitos nos campos sociais, porque esse é um delimitador fundamental para entendermos sua função nesse determinado campo. O "agente", como denomina Bourdieu (2011), detentor de um capital específico se torna diferenciado pelos demais passando a ter uma livre circulação e maior aceitação nesse meio. Mesmo que a quantidade e a forma de acumulação de capital sejam diferentes entre os indivíduos 
quando entram em um campo passam a conjugar ideias e atitudes onde são construídos as estruturas e limites desse campo por meio dos valores conjugados e a igualdade entre os membros, designada como héxis corporal.

Esse entendimento se torna fundamental no momento de analisarmos as "comunidades" da dança de salão como um campo que, segundo Marion "são arenas sociais nas quais as identidades são confirmadas" (2008, p.27), com agentes específicos que validam essas identidades pelos seus discursos e práticas.

Para Bourdieu (1983, p.124), o esquema corporal refere-se a um "depositário do mundo social", de acordo com os grupos sociais em que esses corpos estão inseridos, relacionado à familiaridade e a imediatez da experiência corporal, resultantes do habitus, como articulador entre o individual e o coletivo.

O corpo fala nas relações sociais exprimindo de forma incontestável o que se é. A experiência prática do corpo, que se produz na aplicação, ao corpo próprio, de esquemas fundamentais nascidos da incorporação dessas estruturas sociais, e que é continuamente reforçada pelas reações, suscitadas segundo os mesmos esquemas, que o próprio corpo suscita nos outros, é um dos princípios da construção, em cada agente, de uma relação duradoura para com seu corpo e o campo ao qual pertence.

A soma das disposições incorporadas, movimentos, gestos e técnicas do corpo, resultam em esquemas corporais que traduzem os corpos desses agentes, como um produto social, desde as dimensões de sua conformação visível até nas formas de se portar e se comportar, expressados pela aquisição desses modelos de esquemas corporais que são "aprendidos" e corporificados, refletindo a construção da héxis corporal que se transforma na principal forma de comunicação com os outros agentes.

Os esquemas ou técnicas corporais ocupam uma centralidade nos estudos de Bourdieu, justamente por traduzirem em suas marcas corporais o sentido das relações de poder e dominação traçados pelo agente portador do habitus que se desenvolve em um campo e por ele são moldados, inserindo-se assim, em um contexto social que baliza as ações, características e gestos desses agentes. Para o autor, o vocabulário 
de dominação está repleto de metáforas corporais estampadas na gestualidade do corpo e nos automatismos do cérebro (BOURDIEU, 1983).

\section{PROCESSOS OCULTOS ENTRE DOIS CORPOS}

Tecendo um fio condutor entre o processo de nascimento das danças de salão, analisando seu contexto histórico-cultural com as questões da corporeidade presentes na teoria de Bourdieu, iniciamos uma tentativa de mapear o corpo como representatividade no cenário das danças de salão, no seu início e sua contextualização na contemporaneidade refletindo sobre a estruturação e edificação das disposições nos corpos dos sujeitos envolvidos nessa prática, a partir dessa perspectiva.

Partindo do pressuposto de que, a maneira como cada indivíduo age em sociedade está vinculada, como processo da vida coletiva, a um processo de normatização acentuada, que revela tensões e intenções e não tampouco, resultado de ações isoladas, podemos refletir sobre o surgimento das técnicas corporais como elementos que não são criados de maneira aleatória, mas sim como parte desse processo normativo e dominador, relacionando diretamente, dessa forma, os signos corporais à construção cultural de cada sociedade. E, por mais que pensemos em particularidades de cada região ou época é por meio das comunicações não-verbais (LARA, 2004), que podemos perceber as especificidades corpóreas que denunciam e concretizam as influências formadoras de cada sociedade.

Por meio desse pensamento é possível perceber que essa separação entre o sujeito e sua natureza é realizada em forma de dominação e violência do corpo por meio de formas de tecnificação, uniformização e sofrimento. Mascarada, diversas vezes, por técnicas como as de dança ou dos esportes, que se utilizam dessa formatação para doutrinar ou dominar as pulsões e paixões, próprias da natureza dos sujeitos. 
Nesse sentido, ao voltarmos o olhar para a época e o local onde as danças de salão iniciaram sua trajetória é possível dimensionar as intencionalidades de dominação e freamento de pulsões e desejos corporais, que podem ter influenciado nas técnicas e códigos da criação dessa forma de manifestação cultural, no intuito de, ao revisitar as construções de sua trajetória, poder refletir sobre a utilização e aceitação dessas construções nos dias de hoje.

Para dar lugar a essa reflexão, temos que nos transportar para a sociedade burguesa europeia dos séculos XIV e XV, onde as chamadas sociedades de corte marcaram a história Ocidental, com fortes influências sobre costumes, ditames e condutas até o início do século XIX. O retrato das cidades europeias nesta época está baseado em divisões físicas e culturais e a dança nada mais é do que o resultado desta separação. Os camponeses, burgueses e os nobres, apesar de habitarem locais muito próximos, estavam divididos completamente por questões sociais, culturais e econômicas.

Segundo Elias (2001) podemos destacar o reinado de Luís XIV (1661-1715) na França que ditava regras e condutas sociais seguidas por outras monarquias absolutistas. Nessa sociedade a representação social era fundamental assim, o corpo ganha papel de destaque nesse cenário através da moda, etiqueta e formas de expressões artísticas como a dança, a música e a pintura. Essa soberania de Luís XIV e sua relação com o poder estava inscrita nos modos de exuberância de seus costumes, conhecido como 'Rei Sol', foi um grande admirador das Artes, especialmente da Dança, sendo responsável por fundar a Academia Real da Dança, em 1661.

Como acentua o autor:

Para Luís XIV, a manifestação pública e a representação simbólica do seu poder eram valores em si. Para ele, os símbolos do poder animamse e adotam o caráter de fetiches de prestígio. O fetiche de prestígio que melhor exprime o caráter de valor autônomo da existência do rei é a glória (ELIAS, 2001, p. 108). 
E é nesse contexto, caracterizado como o berço das Danças de Salão que irão se estruturar as técnicas e disposições dessa manifestação cultural, mapeada pelas relações estabelecidas entre a época e a parte da sociedade em que estavam inseridas.

Se pensarmos no corpo que dança, direcionado à cultura popular, compreenderemos um aprendizado sendo balizado por técnicas e estruturas próprias de uma dada comunidade. Essas técnicas estão formatadas de acordo com as tradições ou valores elegidos por aquela comunidade (LARA, 2004). O que nos leva a direcionar nosso olhar às intenções pontuais e normativas que constituem cada sociedade, ou parte dela e que, por serem regidas por grupo dominante acabam por balizar o estabelecimento das regras e técnicas das chamadas danças populares, associando-as como forma de expressão dos dominantes que, revestida de intenções de igualdade e popularidade apresenta-se costurada por finalidades e sentidos distintos, invertendo nessa relação o real significado da palavra popular, que se refere à expressão "do, ou próprio do povo" (FERREIRA, 2008, p. 642).

Os dominados celebram a própria dominação. Eles fazem da liberdade uma paródia, na medida em que livremente se colocam a serviço da cisão, mais uma vez, do indivíduo com seu próprio corpo. Por meio dessa liberdade confirma-se a injustiça, fundada na violência social, que mais uma vez se destina aos corpos escravizados [...] (ADORNO apud VAZ, 2004, p. 27)

Como exemplo dessa dominação, podemos citar a apropriação e descaracterização das danças europeias campesinas em pares anteriores as danças de corte que eram praticadas sem o uso de uma técnica estruturada e formatada e que depois de serem adaptadas e ensinadas aos nobres por meio de artistas chamados de Menestréis, perdem-se suas características originais e dissolvem no tempo por falta de registro. Já que, em conjunto com essa adaptação das danças campesinas para as danças de corte, supõem-se terem se estruturado outros elementos que vinham ao 
encontro de conceitos e condutas dessa nobreza, como por exemplo: os termos 'cavalheiro' e 'dama', utilizados, respectivamente para designar quem detinha o poder e conduziria a dança, no caso o homem e quem estaria na posição de ser conduzida, protegida e não teria direito de escolha, papel da mulher, reafirmando valores e condutas que regiam a vida da nobreza e da qual, a liberdade e espontaneidade presente nas danças campesinas, não faziam parte. "Para a corte, dançar bem, com o devido decoro e o controle de gestos, era uma atividade essencial para a formação de um nobre" (NUNES, 2016, p. 79).

Esses elementos nos fazem refletir sobre a dominação da natureza corpórea, por meio de um conjunto de regras e técnicas que ditavam as estruturas da dança de salão naquele contexto cultural. $\mathrm{O}$ que acaba por gerar o questionamento de como esses códigos e discursos atuam hoje e de que forma eles têm afetado os corpos dos praticantes dessa modalidade.

\section{REFLEXÕES TRANSITÓRIAS}

Ao pensarmos na dança de salão como uma comunidade que segundo (MARION, 2008) se articula como um "campo" onde suas identidades são validadas pelos discursos e formas de agir dos seus participantes podemos refletir sobre a extensão desses grupos e a capacidade que temos hoje em dia, devido ao avanço tecnológico, da propagação de ideias, discursos e práticas serem absorvidas de maneira quase que instantânea por todos os membros e seguidores dessa comunidade. Essa dimensão de campo nos impulsiona a dimensionar de que forma o capital corporal, possuidor de códigos e caracteres age dentro do campo da dança de salão propulsionando seus participantes a se moldarem de acordo com as disposições comuns a esse campo.

$\mathrm{Na}$ construção desse corpo social portador do habitus é que se moldam a um sistema de disposições duradouras que são incorporadas por meio de práticas 
reguladas e estruturadas e que são desenvolvidas marcas corporais que, por diversas vezes, passam despercebidas pelos sujeitos envolvidos, justamente por sua imersão nesse campo. Aqui, não nos cabe à definição de intencionalidade dessas marcas e nem da qualidade delas, apenas nos determos na urgência de olharmos para esse processo que na dança de salão se inicia pelo campo da aprendizagem e se bifurca nas demais manifestações dessa dança e de que forma elas estão relacionadas a estereótipos binários e heteronormativos.

As técnicas corporais ocupam uma centralidade nos estudos de Bourdieu, justamente por traduzirem em suas marcas corporais o sentido das relações de poder e dominação traçados pelo agente portador do habitus, que se desenvolve em um campo e por ele são moldados, inserindo-se assim, em um contexto social que baliza as ações, características e gestos desses agentes. Para Bourdieu (1983), o vocabulário de dominação está repleto de metáforas corporais, estampadas na gestualidade do corpo e nos automatismos do cérebro.

Pensar na relação corpo - sujeito nos possibilita enxergar que os conceitos que empregamos em nosso cotidiano muitas vezes vistos como processos comuns são, por diversas vezes, apenas reproduções de discursos e códigos que vêm carregados de valores de dominação e relações de poder.

O intuito dessa pesquisa não é a de desmerecer a beleza e importância da dança de salão e sim, trazer à tona processos ocultos entre dois corpos que vão muito além de tradições e estruturas e que dizem respeito a toda uma história cultural de violência e discriminação e que estabelecem relações de machismo, binarismo, intolerância e preconceito.

Ao mesmo tempo, objetivamos, nessa perspectiva, entendida a partir do campo de criação das danças de salão, tomar uma dimensão significativa no pensar do corpo, no reconhecimento dessas violências e no estímulo de tomada de consciência que torna o sujeito, aqui especificamente, praticante dessa modalidade de dança, um agente definidor de seus próprios processos, aberto a experimentações e reflexões, que não querem, de forma alguma extinguir com os registros históricos já existentes 
dessa manifestação cultural e sim, alargar o pensamento para outros caminhos e outras possibilidades de pensar, sentir e agir.

\section{REFERÊNCIAS}

ADORNO, THEODOR; HORKHEIMER, MAX. Dialética do esclarecimento: fragmentos filosóficos. Rio de Janeiro: Jorge Zahar, 1985.

BOURCIER, PAUL. História da dança no Ocidente. São Paulo: Martins Fontes, 2016.

BOURDIEU, PIERRE. Gostos de classe e estilos de vida. Pierre Bourdieu: sociologia. Tradução: Paula Montero e Alícia Auzmendi. São Paulo: Ática, 1983.

Observações sobre a história das mulheres. In: As mulheres e a história. Lisboa: Dom Quixote, 1995.

. Meditações pascalianas. Rio de Janeiro. Bertrand Brasil, 2001.

Bertrand Brasil, 2002. jun. 2006.

O camponês e o seu corpo. Revista de Sociologia e Política, Curitiba, n.26, p.83-92,

O senso prático. Petrópolis: Vozes, 2011.

CAMINADA, ELIANA. História da dança: evolução cultural. Rio de Janeiro: Sprint, 1999.

DICKOW, KATIUSCA M. C. Análise da ocorrência de danças a dois na história da dança e sua influência na história da dança de salão. 2010, 57f. Trabalho de conclusão de curso (Pós-graduação em Análise e teoria da dança com ênfase em dança de salão), Faculdade Metropolitana de Curitiba, Curitiba, 2010.

ELIAS, NOBERT. A sociedade de Corte: investigação sobre a sociologia da realeza e aristocracia de corte. Tradução: Pedro Sussekind. Rio de Janeiro: Zahar, 2001.

ELLMERICH, LUIS. História da dança. São Paulo: Ricordi, 1964.

FARO, ANTONIO J.; SAMPAIO LUIZ P. Dicionário de balé e dança. Rio de Janeiro: Zahar, 1989.

FEITOZA, Jonas Karlos de Souza. Danças de Salão: os corpos iguais em seus propósitos e diferentes em suas experiências. 2011. 84p. Dissertação (Mestrado em Dança), Faculdade de Dança, Universidade Federal da Bahia, Salvador, 2011.

FOUCAULT, MICHAEL. A arqueologia do saber. 6 ed. Tradução: Luiz Felipe Baeta Neves. Rio de Janeiro: Forense Universitária, 2002. 
LARA, LARISSA M.. O sentido ético-estético do corpo na cultura popular. 2004. $226 \mathrm{f}$. Tese (Doutorado em Educação), Universidade Estadual de Campinas, Campinas, 2004.

MARION, JONATHAN S. Culture and Costume and Competitive Dance. New York: Berg Publishers, 2008.

MEDEIROS, CRISTINA C. C de. Habitus e corpo social: reflexões sobre o corpo na teoria sociológica de Pierre Bourdieu. Porto Alegre, Revista Movimento, v. 17, n. 01, p. 281-300, jan./mar. 2011.

MILSTEIN, DIANA; MENDES, HECTOR. Escola, corpo e cotidiano escolar. São Paulo: Cortez, 2010.

NUNES, BRUNO B. O fascínio das danças de Corte. Curitiba: Editora Appris, 2016.

PAZETTO, DĖBORA.; SAMWAYS, SAMUEL. Para além de damas e cavalheiros: Uma abordagem Queer das normas de gênero na dança de salão. Florianópolis, Revista Educação, Artes e Inclusão, v.14, n.3, jul./set. 2018.

PERNA, MARCO. A. Dama boa não pensa... In: (Org.). 200 Anos de Dança de Salão no Brasil - Vol. 2. Rio de Janeiro: Amaragão Edições de Periódicos, 2012. p. 47-53.

POPULAR. In: FERREIRA, A. B. de H. Dicionário Aurélio da língua portuguesa. Curitiba: Positivo, 2008.

RIED, BETINA. Fundamentos da dança de salão. São Paulo: Editora Phorte, 2003.

SILVEIRA, PAOLA V. Diálogos de um ser a dois: uma perspectiva para dançar tango. 2012. 40f. Trabalho de Conclusão de Curso (Graduação), Escola de Educação Física, Fisioterapia e Dança, Universidade Federal do Rio Grande do Sul, Porto Alegre, 2012.

STRACK, Míriam Medeiros. Dama ativa e comunicação entre o casal na dança de salão: uma abordagem prática. 2013. 76p. Monografia (Especialização em Teoria e Movimento da Dança com Ênfase em Danças de Salão), Faculdade Metropolitana de Curitiba (FAMEC), São José dos Pinhais, 2013.

TAVARES, ISIS M. Educação, corpo e arte. Curitiba: IESDE, 2005.

VAZ, ALEXANDRE. F. Corporalidade e Formação na obra de Theodor W. Adorno: questões para a reflexão crítica e para as práticas corporais. Florianópolis, Revista Perspectiva, v.22, p. 21-49, jul./dez. 2004.

VECCHI, RODRIGO. L. O ensino da Dança de Salão pautado na teoria do "Teaching for Understading." 2012. 215f. Tese (Doutorado em Educação Física), Faculdade de Educação Física, Universidade São Judas Tadeu, São Paulo, 2012. 